WSRC-RP-92-245

\title{
OVERVIEW OF A CONCEPTUALIZED WASTE WATER TREATMENT FACILITY FOR THE CONSOLIDATED INCINERATOR FACILITY (U)
}

by D. J. McCabe

Westinghouse Savannah River Company

Savannah River Site

Aiken, South Carolina 29808

DE93 002170

This paper was prepared in connection with work done under Contract No. DE-AC09-89SR18035 with the U. S. Department of Energy. By acceptance of this paper, the publisher and/or recipient acknowledges the U.S. Government's right to retain a nonexclusive, royalty-free license in and to any copyright covering this paper, along with the right to reproduce and to authorize others to reproduce all or part of the copyrighted paper.

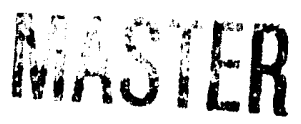




\section{DISCLAIMER}

This report was prepared as an account of work sponsored by an agency of the United States Government. Neither the United States Government nor any agency thereof, nor any of their employees, makes any warranty, express or implied, or assumes any legal liability or responsibility for the accuracy, completeness, or usefulness of any information, apparatus, product, or process disclosed, or represents that its use would not infringe privately owned rights. Reference herein to any specific commercial product, process, or service by trade name, trademark, manufacturer, or otherwise does not necessarily constitute or imply its endorsement, recommendation, or favoring by the United States Government or any agency thereof. The views and opinions of authors expressed herein do not necessarily state or reflect those of the United States Government or any agency thereof.

This report has been reproduced directly from the best available copy.

Available to DOE and DOE contractors from the Office of Scientific and Technical Information, P.O. Box 62, Oak Ridge, TN 37831; prices available from (615) 576-8401, FTS 626-8401.

Available to the public from th: National Technical Information Service, U.S. Department of Commerce, 5285 Port Royal Rd., Springcield, VA 22161. 
Keywords :

Consolidated

Incinerator Facility

February 7, 1992
TO: D.L.
FROM: D. $7:$ McCabe, $676-\mathrm{T}$

\section{SUMMARY}

The offgas system in the Consolidated Incinerator Facility (CIF) will generate an aqueous waste stream which is expected to contain hazardous, nunhazardous, and radioactive components. The actual composition of this waste stream will not be identified until startup of the facility, and is expected to vary considerably. Wastewater treatment is being considered as a pretreatment to solidification in order to make a more stable final waste form and to reduce disposal costs. A potential treatment scenario has been defined which may allow disposition of this waste in compliance with all applicable regulations.

The conceptualized wastewater treatment plant is based on literature evaluations for treating hazardous metals. Laboratory tests hwill be run to verify the design for its ability to remove the hazardous and radioactive components from this waste stream. The predominant mechanism employed for removal of the hazardous and radioactive metal ions is coprecipitation. The literature indicates that reasonably low quantities of hazardous metals can be achieved with this technique. The effect on the radioactive metal ions is not predictable and has not been tested. The quantity of radioactive metal ions predicted to be present in the waste is significantly less than the solubility limit of those ions, but is higher than the discharge guidelines established by DOE Order 5400.5 .

\section{INTRODUCTION}

The CIF offgas system incorporates an aqueous quench and an alkaline scrubber. These streams can be recycled and concentrated up to 10 wto salt and 10 wto flyash (1). The predominant soluble species is expected to be sodium chloride. Appreciable levels of soluble hazardous metals and radionuclides are expected as well. Separation of the sodium chloride and the majority of the water from the hazardous and radioactive components would simplify the solidification process, reduce the disposal costs, and generate a more durable waste form. An acceptable solidification method has not been demonstrated for wastes containing high concentrations of sodium chloride. Several technical issues would need to be 
resolved before glass encapsulation could be considered an acceptable solidification matrix, although it may prove to be feasible. The need exists for developing a treatment scenario which would remove the hazardous and radioactive components to a low level and allow discharge of the sodium chloride solution.

Waste Management Technology (WMT) has requested that IWTS develop a treatment scenario which would allow for disposal of the waste constituents in compliance with all applicable regulations. A conceptualized treatment plant has been formulated (Figure 1 ). Experimental work will be conducted to demonstrate the ability of this treatment plant to remove hazardous constituents to an acceptable level. This document addresses the logic used in the selection of treatment steps to remove the hazardous and radioactive constituents.

\section{BACKGROUND}

Typical wastewater treatment plants which are designed to remove hazardous metals employ $\mathrm{pH}$ adjustment (2). Most of the heavy metals can be precipitated in the hydroxide form by adjustment to $\mathrm{pH}$ 10-11, and clarified (Table 1). The remaining fraction, which is soluble, normally approaches the solubility limit of the metal hydroxide. Flocculation and coprecipitation are typically employed to achieve separation below the solubility limit. The most common method is the addition of iron(III) chloride under acidic conditions with subsequent precipitation at slightly alkaline conditions. Since each waste stream is different, laboratory and pilot-scale tests on the waste stream are necessary to develop a workable treatment scenario. Use of iron (III) chloride or iron(III) sulfate are considered interchangeable for the purposes of this document.

Special treatments are required when waste streams contain chromium(VI), mercury, and selenium. The chromium(VI) must be reduced to the +3 oxidation state, which is much less soluble. The mercury and selenium salts must be precipitated as the sulfide salts, which are much less soluble than the hydroxide salts. The remaining sulfide must then be removed before the water is discharged.

The radionuclides which are predicted to be present in the stream (3) present problens which have not been fully addressed in the literature. The quantity of material present (Table 2), expressed as $\mathrm{mg} / \mathrm{L}$, is exceedingly small and is only directly measurable by modern analytical techniques if the metal ions present are radioactive. Removal of metal ions to such a low level is not commonly done and is only of concern if the metal ions are radioactive. The DOE discharge guidelines (5) set maximum limits on the concentration of radionuclides in the outfall which are often several orders of magnitude below the metal hydroxide solubility. Direct precipitation is thus impossible, leaving coprecipitation as the only possible separation technique. Techniques such as reverse osmosis and electrodialysis will not selectively separate sodium chloride from the other salts. Ion exchange resins are not expected to be capable of removing such a wide variety of metal ions to a low level in a sodium chloride 
solution. The regenerate solution from the ion exchange resin would also need to be treated for disposal.

The conceptualized flow sheet is similar to many wastewater treatment plants designed to remove a variety of nonradioactive waste constituents. The design is more extensive than the Oak Ridge Central Neutralization Facility which uses precipitation and flocculation for metal ion removal (6). The waste generated in the Oak Ridge $\mathrm{K}-25$ mixed waste incinerator contains considerably lower levels of hazardous and radioactive constituents than are expected in the CIF. The single test of the facility was of limited duration and generated blowdowns which contained hazardous metals only slightly above the drinking water limits. The conceptualized flow sheet is somewhat similar to that for the Rollins Environmental plant, although data for that plant is rather limited (7).

\section{CONCEPTUAIIZED ELOW SHEET DESCRIPTION}

A flow equalization tank capable of attenuating the variability in waste composition will minimize the quantity of waste which does not meet the discharge criteria and must be recycled. A tank capable of containing four days accumulation of waste should be adequate. At a design flow rate of 10 GPM from the CIF, this would be a 58,000 gallon tank. The design flow rate for the treatment process is $20 \mathrm{GPM}$, which allows for $50 \%$ utility. Chlorine must be added to the tank to prevent bacterial growth if the sodium chloride concentration is below 0.5 wt $\%$. Agitation must be vigorous enough to suspend the ash solids.

The solution would be $\mathrm{pH}$ adjusted with lime or magnesia (or another reagent) in an agitated $\mathrm{pH}$ adjustment tank to $\mathrm{pH}=10-11$. This would precipitate the majority of the insoluble metal hydroxides.

Addition of a polymeric flocculating agent would allow rapid flocculation of the metal hydroxides. The hydroxides and most of the flyash could then be removed in the clarifiers. Depending on the settling rates, which would be determined in tests, two clarifiers (one lamella, one circular) may be needed. The sludge from these would be sent to a filter press for further dewatering. The overflow from the clarifiers would pass to an agitated reaction tank where sulfuric acid and ferrous sulfate would be added. The $\mathrm{pH}$ would be maintained at approximately $\mathrm{pH}=2.5$.

Solutions of iron(III) sulfate and aluminum sulfate would next be added to the wastewater. The expected wastewater concentraticr. required would be $500-1000 \mathrm{ppm}$ of $\mathrm{Fe}$ (III) and $200 \mathrm{ppm}$ of AI(III). The solution would be neutralized in the next step with an alkaline reagent, and sodium sulfide would be added concurrently. (A failsafe system must be designed to prevent the addition of sodium sulfide to an acidic waste solution, which would generate hydrogen sulfide gas.) The wastewater would then be fed to the filter feed/concentrate tank.

The crossflow microfilter would recycle the waste until it is concentrated to 5 wt total suspended solids (TSS). When the waste reaches 5 wto TSS, the feed/concentrate tank would pump to 
the high pressure filter press. The permeate from the microfilter would be chlorinated to prevent biological growth, and sent to an ion exchange resin.

The ion exchange resin (or $\bar{a}_{\text {in }}$ zeolite) would remove cesium ions, which are not expected to be appreciably removed at any other point in the process. Considerable shielding may be necessary due to the anticipated high activity of the loaded resin. The ion exchange effluent would be $\mathrm{pH}$ adjusted to $\mathrm{pH}=7$ and sent to the activated carbon. The activated carbon is designed to absorb any organic material present, hydrogen sulfide, and residual quantities of metal ions. The effluent from the carbon bed is collected in a hold tank and analyzed for compliance prior to discharge. If the water does not meet the discharge criteria, it must be recycled to the equalization tank.

The filtrate from the high pressure filter press is recycled to the equalization tank. The solids in the filter are rinsed with clean process water, and the rinse water is sent to the equalization tank. The solids from the filter press are discharged as a cake for solidification. Two cleaning tanks for the crossflow microfilters would allow reuse of the cleaning solutions until they are exhausted. The waste cleaning solution would be returned to the flow equalization tank. The spent ion exchange resin and spent granular activated carbon would be burned in the incinerator, assuming that the cesium species present is not volatile in the incinerator.

\section{DISCUSSION}

\section{Solubilities}

Table 1 is a compilation of hazardous metal solubility data from various sources (8). The predicted maximum concentration for each metal is listed (1). The theoretical solubility of each metal at $\mathrm{pH} 10$ is derived from either the solubility product constants or from tables containing the distribution of hydrolysis products and thei: solubilities. The optimum pH to achieve the minimum solubility for the individual metal hydroxides was obtained from operating data or empirical evidence from different waste treatment plants $(2,4)$. A corresponding minimum solubility at the optimum $\mathrm{pH}$ of the metal hydroxides in the treated water is also listed. These examples are from various waste streams from different sources where the initial concentrations of each metal varies widely. These examples are presented only for general comparisons. Normally, these values are from the analysis of clarifier overflows after $\mathrm{pH}$ adjustment with lime and subsequent flocculation. The optimum $\mathrm{pH}$ for $\mathrm{Fe}$ coprecipitation and the solubility of the resulting metal ion in the clarified water is also listed in Table 1. The optimum pH for iron coprecipitation not incidentally corresponds with the minimum zeta potential for iron(III) hydroxide and therefore the minimum solubility. The EPA drinking water limits are listed for reference.

In general, the precipitation of metal hydroxides with lime is not adequate to meet discharge criteria. The solubility of the metal hydroxides in actual waste streams may not correspond with that predicted based solely on $\mathrm{pH}$. Complexes formed with species other 


$$
-5-\quad \text { WSRC-RP- } 92-245
$$

than hydroxide ions may increase or decrease the solubility. Salting-out effects can occur with unlike ions, common-ion effect can occur with like ions. Silver chloride, for example, is extremely insoluble, but increases as the amount of chloride increases. Alternatively, the solubilities of lead and barium are often far below that predicted due to formation of carbonate salts, which have very low solubilities.

Table 2 contains the concentration of radionuclides which have been predicted to be present in the CIF blowdown (3). The concentration is listed as both the $\mathrm{pCi} / \mathrm{mL}$, and $\mathrm{ppm}(=\mathrm{mg} / \mathrm{L})$. The solubility of most of the metals at $\mathrm{pH} 7$ is also listed. The quantity of radionuclides predicted to be present in CIF blowdowns are typically several orders of magnitude below the solubility limit. The DOE recommended discharge guidelines (RDG) from DOE Order 5400.5 are listed in both $\mathrm{pCi} / \mathrm{mL}$ and $\mathrm{ppm}$. The decontamination factor (Df) required to reduce the predicted quantity to the DOE RDG is included. The "other B/G" includes the beta/gamma emitting radionuclides which are not included in the DOE order. The quantity predicted accounts for almost half of the total beta/gamma activity (excluding tritium, which is not treated in this scenario). The role of these non-listed radionuclides in the conceptualized wastewater treatment plant is not addressed but may be significant.

\section{Treatment Steps}

The initial $\mathrm{pH}$ adjustment with lime or magnesia is done to remove the majority of the hazardous metal ions (Figure 1). As can be seen from Table 1, the optimum $\mathrm{pH}$ is 10-11. The reagent used for pH adjustment would be determined in laboratory or pilot-scale testing, but lime is often used in wastewater treatment plants. Magnesia, calcium carbonate, sodium hydroxide, and other reagents have been used, depending on the morphology of the waste. Lime or magnesia usually yield higher density particulates which allow a better separation in the clarifiers.

The majority of the hazardous metals and radionuclides are expected to be entrapped in the flyash particles which are removed from the waste stream in the clarifiers. Removal at this point prevents extraction of metal ions from the ash upon addition of acid to the waste stream. The acid is added to speed the reaction between iron(II) ions and $C r$ (VI) ions to form the more insoluble Cr(III) hydroxide. The acid also allows dissolution of the iron(III) and aluminum(III) salts prior to coprecipitation. The benefits of iron(III) coprecipitation chemistry have already been discussed, and aluminum(III) may also behave similarly. An air sparge may be required at this point in order to oxidize any remaining $\mathrm{Fe}$ (II) to $\mathrm{Fe}$ (III).

As can be seen from the data in Table 1, some of the metal hydroxides are relatively soluble in alkaline medium. In particular, the minimum solubility of mercury is approximately $75 \mathrm{ppm}$. Reaction of sodium sulfide with most of the heavy metals form metal sulfides which have extremely low solubilities. The mixture of metal hydroxides and sulfides can be concentrated in a crossflow microfilter or ultrafilter to 5-10 wto TSS. The 
concentrate would be sent to the filter press to remove the remaining water to obtain a cake containing 70 wto TSS.

Chlorination of the microfilter permeate water would be necessary if the sodium chloride content is less than 0.5 wto in order to prevent biological growth. An in-line chlorine monitor would ensure accurate dosages to biostatic levels $(\sim 0.5 \mathrm{ppm}$ total residual chlorine). Additionally, chlorine will oxidize most of the remaining sulfide. An ion exchange resin or zeolite capable of removing cesium ions to an acceptable discharge level and tolerant of chlorine is necessary. A Df of 1028 is necessary, based on information provided in Table 2 .

A final pH adjustment is necessary to ensure that the effluent is in the $\mathrm{pH}=6-9$ range, which is normally required in discharge streams. The optimum $\mathrm{pH}$ in the coprecipitation step may be slightly above this range, and provision for correcting that must be made. Also, conversion of the sodium sulfide to dissolved hydrogen sulfide is necessary to ensure its removal. The activated carbon bed absorbs hydrogen sulfide and most organic compounds present. In addition, residual heavy metals and some radionuclides will be extracted by the activated carbon.

\section{Assumptions}

Concentrations of hazardous metals and radioactive metals present in the waste water were obtained from previous documents and were assumed to be the amount present in the waste water $(1,3)$. For the purposes of preparing a simulant, the metal ions are assumed to be in a soluble phase. In the actual waste, it is possible that most of the metal ions are contained in the refractory-like flyash solids, depending on burn conditions. These solids are expected to have particle sizes of less than 3 microns. It was assumed that the sodium chloride-containing effluent could be discharged.

\section{Effluent Composition}

Appropriate environmental assessments and permit negotiations would need to be completed prior to finalizing the design of a wastewater treatment facility. The effluent from the conceptualized plant is expected to contain hazardous metals near the levels listed in Table 1 as the solubility for Fe(III) coprecipitation. For the metals with no listed examples of $\mathrm{Fe}$ (III) coprecipitation, the minimum solubility at optimum $\mathrm{pH}$ shou?d be used for the estimate. The mercury is expected to be approximately $0.1 \mathrm{ppm}$ after precipitation with sulfide. The zinc will also precipitate as the sulfide to approximately $0.01 \mathrm{ppm}$. Overall, removal efficiencies by metal hydroxide precipitation and sulfide precipitations can be from $80 \%$ to $99.9 \%$, depending on metal ion of interest, $\mathrm{pH}$, anions present, and other factors. Residual sulfide concentrations must also be considered in determining discharge criteria.

The quantity of radioactive metal ions present in the effluent is not predictable. The results from laboratory experiments will indicate the expected effluent levels. It is possible that the conceptualized treatment scenario will not remove some of the 
radioactive metal ions to below the DOE RDG, this must be considered in establishing discharge guidelines for the facility. Removal efficiencies for such low concentrations of metal ions have not been determined, but are expected to be lower than for metal hydroxides near their solubility limits. The amount of tritium in the effluent will not be affected by the conceptualized treatment scenario.

The input feed to the CIF will be variable, which leads to a variable waste stream. The amount of polyvinyl chloride in the feed will determine the amount of chloride in the blowdowns, which will indirectly effect the amount of other constituents. The quench and scrubber system can be run in a more dilute mode (i.e. the waste water would be removed from the system before it becomes saturated with sodium chloride and suspended solids). The total dissolved solids content and total suspended solids content can vary from 10 wt: each, to less than 0.1 wt $\frac{}{8}$ by reducing the cycle time between blowdowns. The optimum concentrations will be determined from laboratory testing on waste water simulants. The amount of sodium chloride in the effluent would not be affected by the conceptualized treatment scenario. The amount of chloride present would exceed the drinking water standard, and should be taken into account when determining an outfall and discharge permit.

The EPA drinking water standards also limit the amount of chlorinated hydrocarbons, copper, iron, sulfate, and fluoride. The hydrocarbons are assumed to be removed by the carbon bed. The amount of copper expected in the blowdowns has not been determined, but its solubility at $\mathrm{pH}=10$ is less than $0.01 \mathrm{ppm}$ (2). Iron would be removed to its solubility limit (< $0.01 \mathrm{ppm})$ by the microfilter. Sulfate and fluoride concentrations would not be appreciably affected in the conceptualized treatment scenario.

The secondary wastes produced, spent ion exchange resin and spent carbon, could be burned in the incinerator, assuming no volatile metal species are absorbed. Some cesium compounds are volatile at $1100{ }^{\circ} \mathrm{C}$, just above the temperature of the primary incinerator chamber of. The waste sludge must be solidified for disposal, and the solidification technique must be identified. The volume of waste sludge will be dependent on the amount of acid, caustic, and iron(III) and aluminum(III) salts which must be added, the amount of calcium (and magnesium) carbonate which precipitates, and the ease of dewatering the sludge.

\section{CONCLUSIONS}

Based on literature reviews, the conceptualized treatment plant is expected to remove most of the hazardous constituents to a reasonably low level. The fate of the radionuclides is not known. Laboratory and pilot-scale testing is necessary to ensure that this conceptualized treatment scenario will remove the hazardous and radioactive components to a level which can be discharged, while producing a waste sludge which can be solidified in an acceptable form. 


\section{REFERENCES}

1. D.B. Burns, "CIF Blowdown Simulant for Treatment Studies (U)", WSRC-TR-92-0052, January 30, 1992.

2. J.W. Patterson, "Industrial Wastewater Treatment Technology, Second Edition" Butterworths, 1985.

3. H. Holmes-Burns, "Radionuclide Distribution in the CIF Blowdown (U) " WER-WMT-92-103, February 5, 1992.

4. S.D. Faust, O.M. Aly, "Chemistry of water Treatment" Butterworths, 1983.

5. H. Holmes-Burns, "Wastewater Treatment Limits on CIF Blowdown" WER-WMT-91-0084, October 29, 1991.

6. W.D. Bostick, D.H. Bunch, L.V. Gibson, D.P. Hoffman, J.L. Shoemaker, "Effluent Testing for the Oak Ridge Mixed Waste Incinerator: Emissions Test for August 27, 1990", K/QT-389, December 1990 .

7. D.J. McCabe, C.A. Langton, E.G. Orebaugh, L.B. Burns, H. Holmes-Burns, "Trip Report: Treatment of Incinerator Wastewater at Ft. Dix and Rollins Environmental (U) ", IWT-LWP-91-155, November 26, 1991 .

8. Baes, C., Mesmer, R.; "Hydrolysis of Cations", J. Willey, 1976; and Perry, R.; Chilton, C.; Kirkpatrick, S.; "Perry's Chemical Engineers Handbook, Fourth Edition", McGraw-Hill, 1963.

CC: W.I. Tamosaitis, 773-A

M.G. Looper, 676-1T

W.E. Stevens, 773-43A

A.W. Wiggins, $241-84 \mathrm{H}$

H. Holmes-Burns, 704-61S

S.T. Wach, 703-H

C.A. Langton, 773-43A

E.G. Orebaugh, 773-43A

K.S. Wierzbicki, 703-H

J.P. Bibler, 773-A

W.S. Carnes, 704-61S

D.A. Salem, 704-61S

S.E. Crook, 703-H

W.S. King, 704-61S

C.F. Hair, 773-43A

SRL Records, 773-A (4 copies) 
年

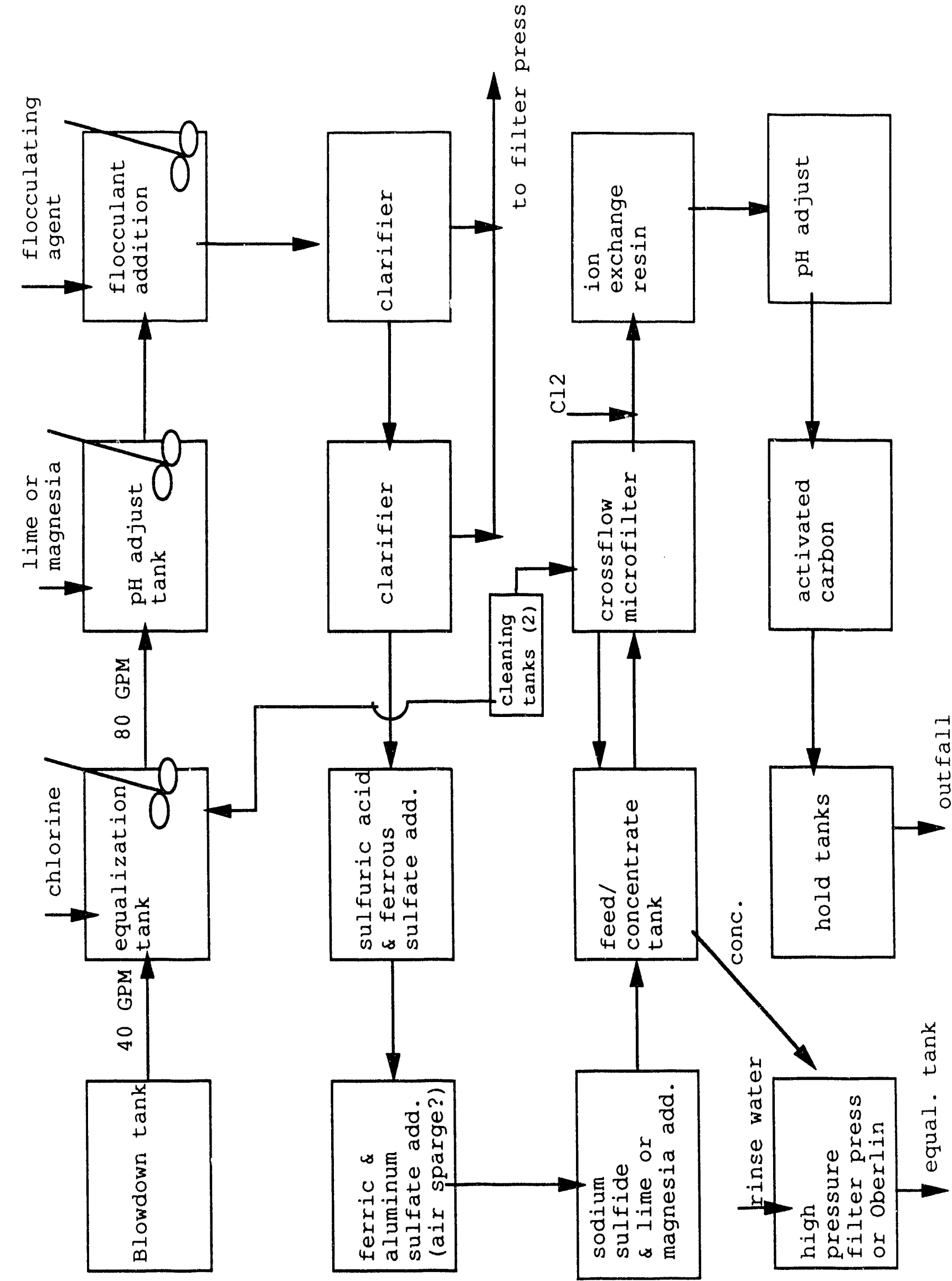




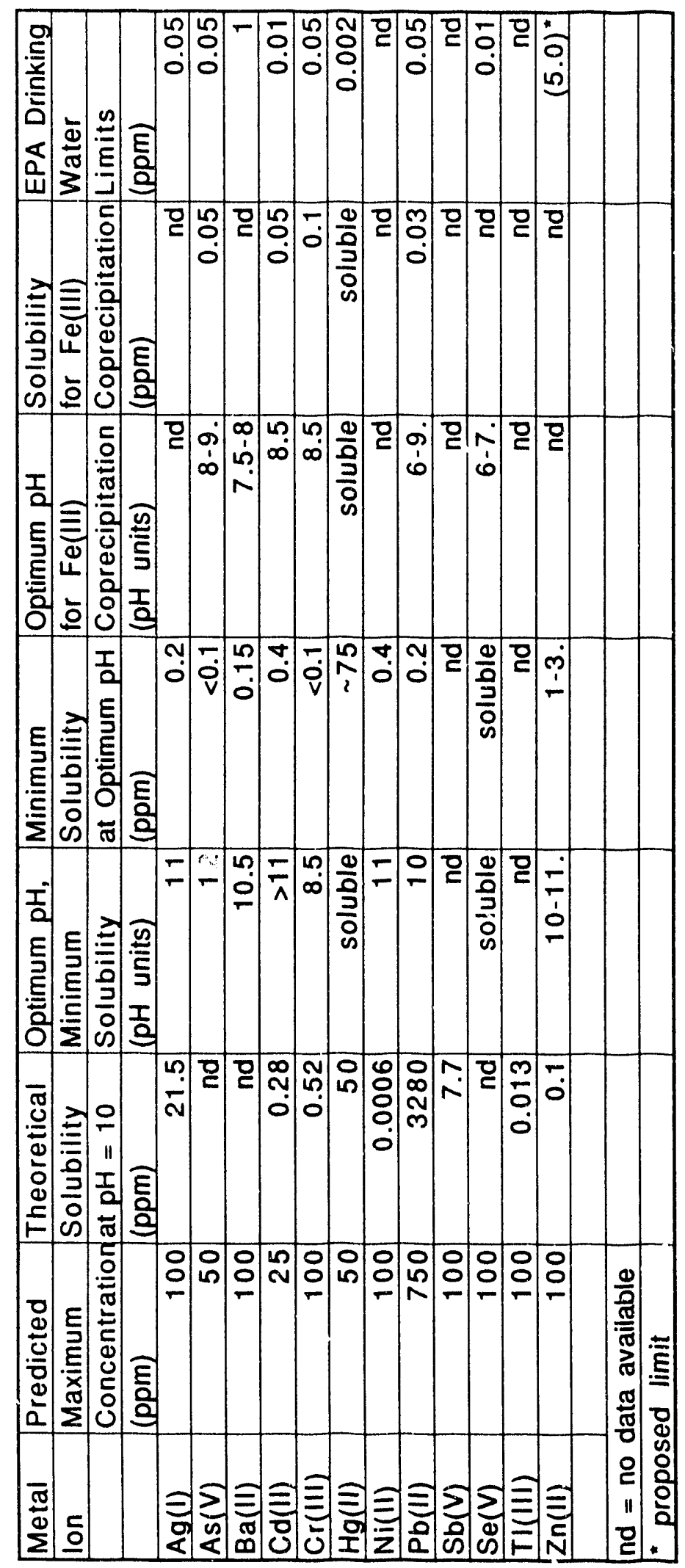




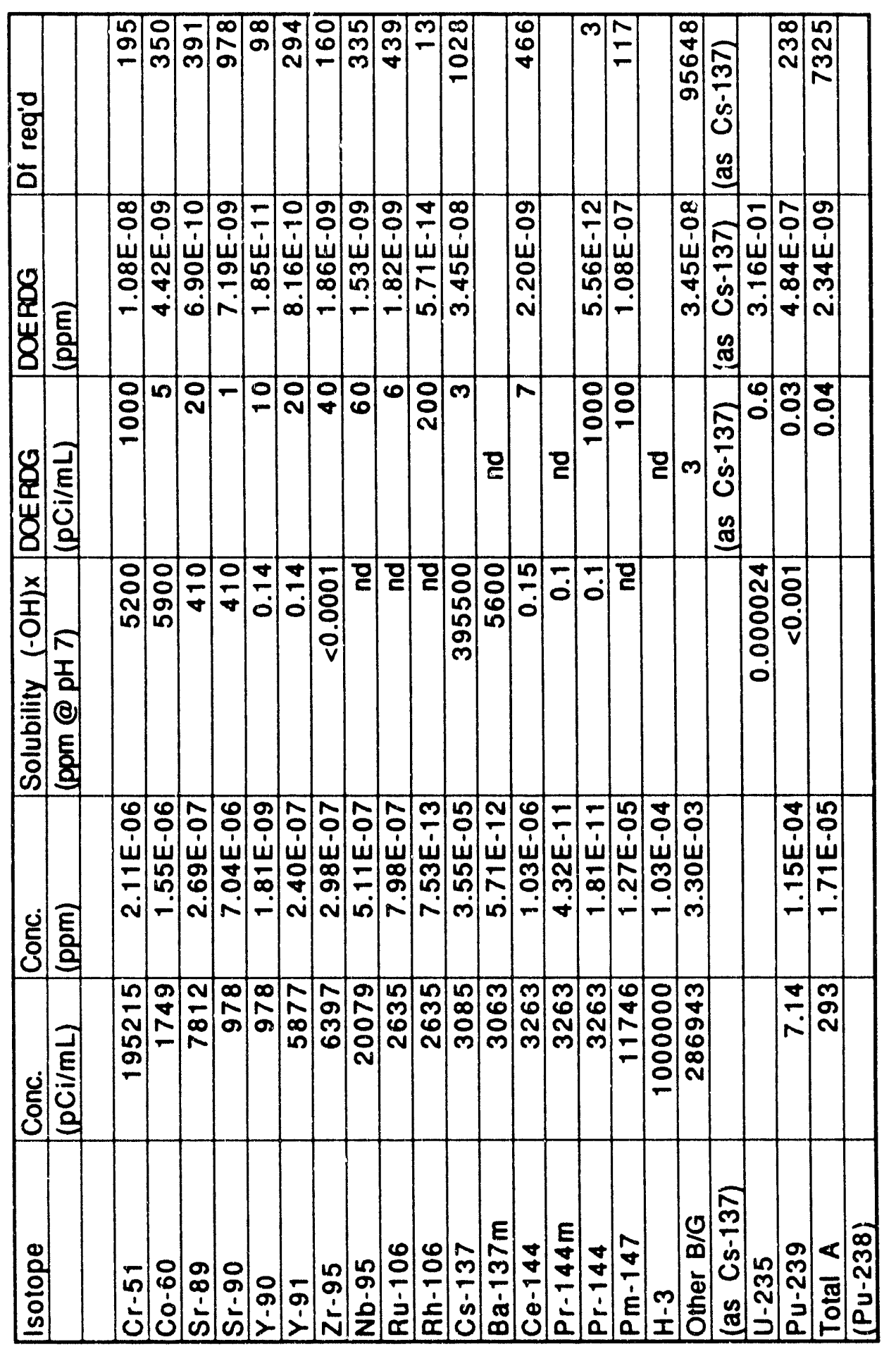



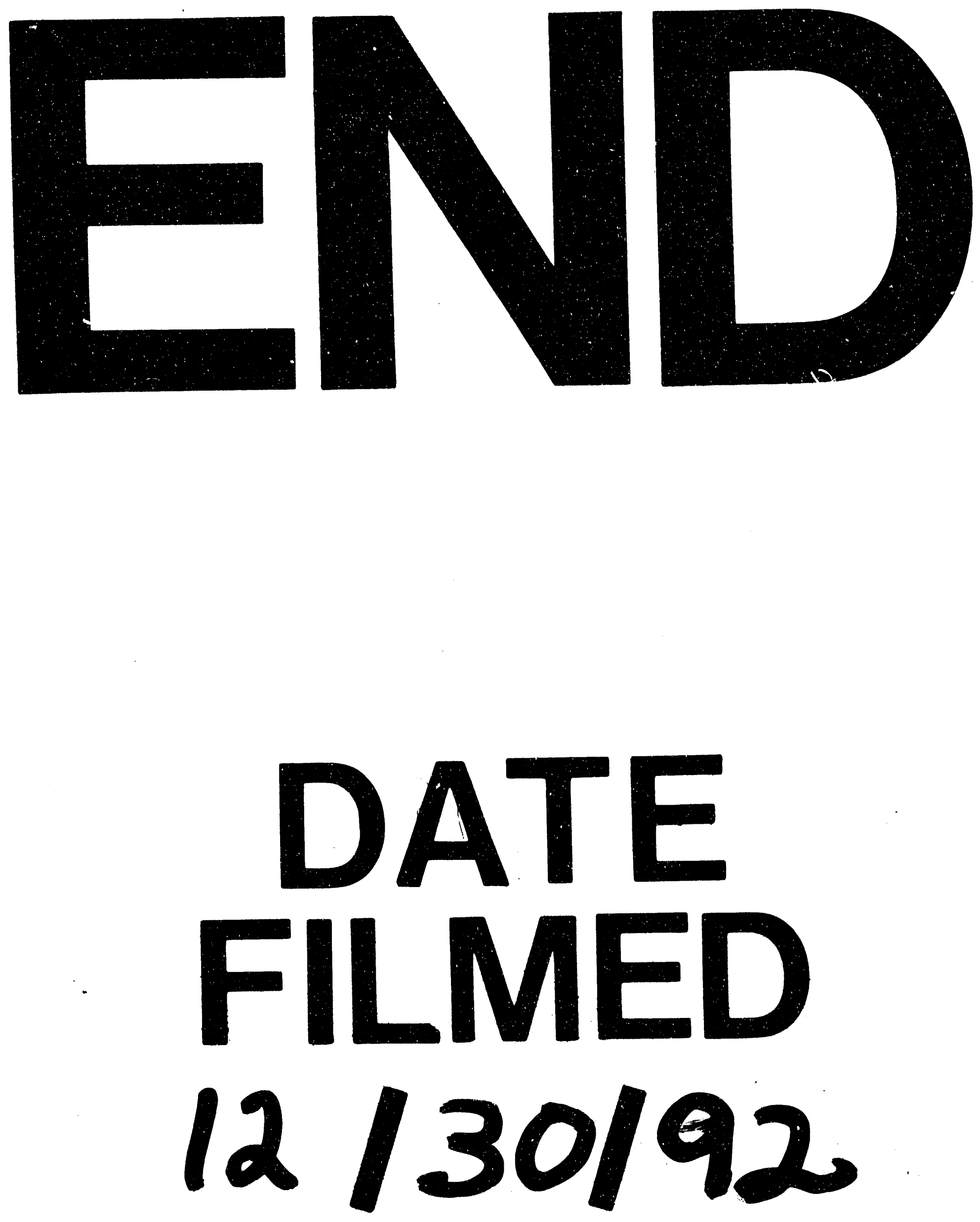
